\title{
4. MAGNETIC-SUSCEPTIBILITY MEASUREMENTS OF METAL CONTAMINANTS IN ODP LEG 101 CORES ${ }^{1}$
}

\author{
William W. Sager, Texas A\&M University, College Station, Texas ${ }^{2}$
}

\section{INTRODUCTION}

Although the techniques of ocean drilling have improved tremendously since the early days of the Deep Sea Drilling Project, it is still common to recover samples that have been disturbed by the drilling process. One type of disturbance, largely overlooked in the literature, is contamination of the cores by metal fragments. By its very nature, the drilling process is one of abrasion. Shards of metal from drill bits and fittings occur in cores from time to time. However, metal contamination by flakes of rust is usually much harder to detect because the flakes can be small and disseminated throughout the core material. On Leg 101, rust contamination was found to be pervasive. Usually, several percent of the core material from each hole appeared to be infiltrated by rust, but in at least one case, Hole $632 \mathrm{~A}$, this figure was nearly $20 \%$.

Nearly 10,000 whole-core magnetic-susceptibility measurements were made on Leg 101. These measurements resulted in an ability to detect metal contamination with a high degree of reliability. The purpose of this report is to summarize these results in order to familiarize future ODP scientists with the use of magnetic susceptibility as a tool for detecting core material that is contaminated by metal. Moreover, it is hoped that this report will increase the awareness of the ocean drilling community to this problem so that steps can be taken to identify such contamination and minimize its effects.

\section{SUSCEPTIBILITY MEASUREMENTS}

Magnetic susceptibility expresses the response of a material to an external magnetic field. It is a fundamental property of all matter related to the arrangement and properties of the atoms and molecules in the medium. Susceptibility is the constant, k, with which the external magnetizing field, $H$, is multiplied to obtain the magnetization, $M$, induced within the material:

$$
M=\mathrm{k} \cdot H .
$$

In general, there are two types of induced magnetism, diamagnetism and paramagnetism. Diamagnetism results from the distortion, caused by the external magnetic field, of electronic orbits in the atoms of a material. For diamagnetic materials, $\mathrm{k}$ is small and negative. Larger positive values of $\mathrm{k}$ are found for paramagnetic substances. Paramagnetism is caused by the reorientation of atoms and molecules with permanent magnetic dipole moments within a substance when an external magnetic field is applied.

Volume magnetic-susceptibility measurements were made on board the JOIDES Resolution using a Bartington Instruments model MS-1 susceptibility meter with a 100 -mm-diameter sen-

\footnotetext{
${ }^{1}$ Austin, J. A., Jr., Schlager, W., Palmer, A. A., et al., 1986. Proc., Init. Repts. (Pt. A), ODP, 101.

2 Address: Department of Oceanography, Texas A\&M University, College Station, TX 77843.
}

sor coil. On its most sensitive scale, the instrument displays susceptibility digitally in units of $1 \times 10^{-7} \mathrm{cgs}$ (the measurements were recorded in the more familiar cgs-centimeter-gram-second-units, which can be converted to SI units by the following relation, $\mathrm{k}_{\mathrm{si}}=4 \pi \cdot \mathrm{k}_{\mathrm{cgs}}$ ). Repeat measurements were run in several instances, and the variation in measurement was only rarely detectable at this sensitivity. Whole-core sections, $1.5 \mathrm{~m}$ in length, were measured at intervals of $10 \mathrm{~cm}$ (occasionally $20 \mathrm{~cm}$ ), downcore. Zero measurements were made before and after each core section, and a linear drift correction was determined. The meter was very stable aboard ship, and the drift corrections were always very small.

The sediments and rocks drilled on Leg 101 are mostly carbonate rich and contain little magnetic material. The geologically significant susceptibility measurements in the lower part of Hole 626C and Holes 627B through 635B range from $-0.4 \times$ $10^{-6} \mathrm{cgs}$ to about $5 \times 10^{-6} \mathrm{cgs}$ (these susceptibility measurements are discussed in detail in the sections on "Paleomagnetism" in each of the site summary chapters in this volume). As both calcium carbonate and water are diamagnetic (Collinson, 1983), the negative susceptibility values are thought to correspond to water-saturated carbonate ooze essentially void of magnetic materials. The weak paramagnetic readings probably resulted from a small amount of iron-bearing minerals present in some sediments. Much larger susceptibilities were recorded for material contaminated with metal fragments, as discussed below.

In Figure 1, susceptibility measurements are plotted vs. depth for most of the Leg 101 holes. The most striking features of these records are the large-amplitude spikes recorded at approximately regular intervals downhole. It became apparent that the spikes are not obviously related to geologic strata within the core material. Examinations of the material producing the high susceptibility readings found that it contained rust fragments ranging in size from a fraction of a millimeter to about $1 \mathrm{~cm}$. Armed with this finding, further investigations of susceptibility "anomalies" were undertaken. Although these investigations were not exhaustive, they were sufficient to characterize most of the metal contamination that occurred on Leg 101.

The anomalous susceptibility measurements fall into two categories: those that occur at core boundaries and those that occur randomly. The random anomalies were usually detected by a rapid rise in susceptibility over a depth of only a few tens of centimeters. One such record, from Section 2 of Core $631 \mathrm{~A}-2 \mathrm{H}$, is shown in Figure 2. The susceptibility changes from slightly paramagnetic $\left(0.2-0.4 \times 10^{-6} \mathrm{cgs}\right)$ to a value of $355 \times 10^{-6} \mathrm{cgs}$ over a depth of $40 \mathrm{~cm}$. The cause was found to be a large chunk of metal from the drilling apparatus. Flanges, pins, wire, and chunks of drill bit were all excavated from Leg 101 core material after being located by similar susceptibility anomalies. In several instances, it was possible to locate large metal fragments merely by passing the portable fluxgate magnetometer over the core sections.

Susceptibility anomalies located at core boundaries could be traced to rust contamination of the core material. Of these anoma- 


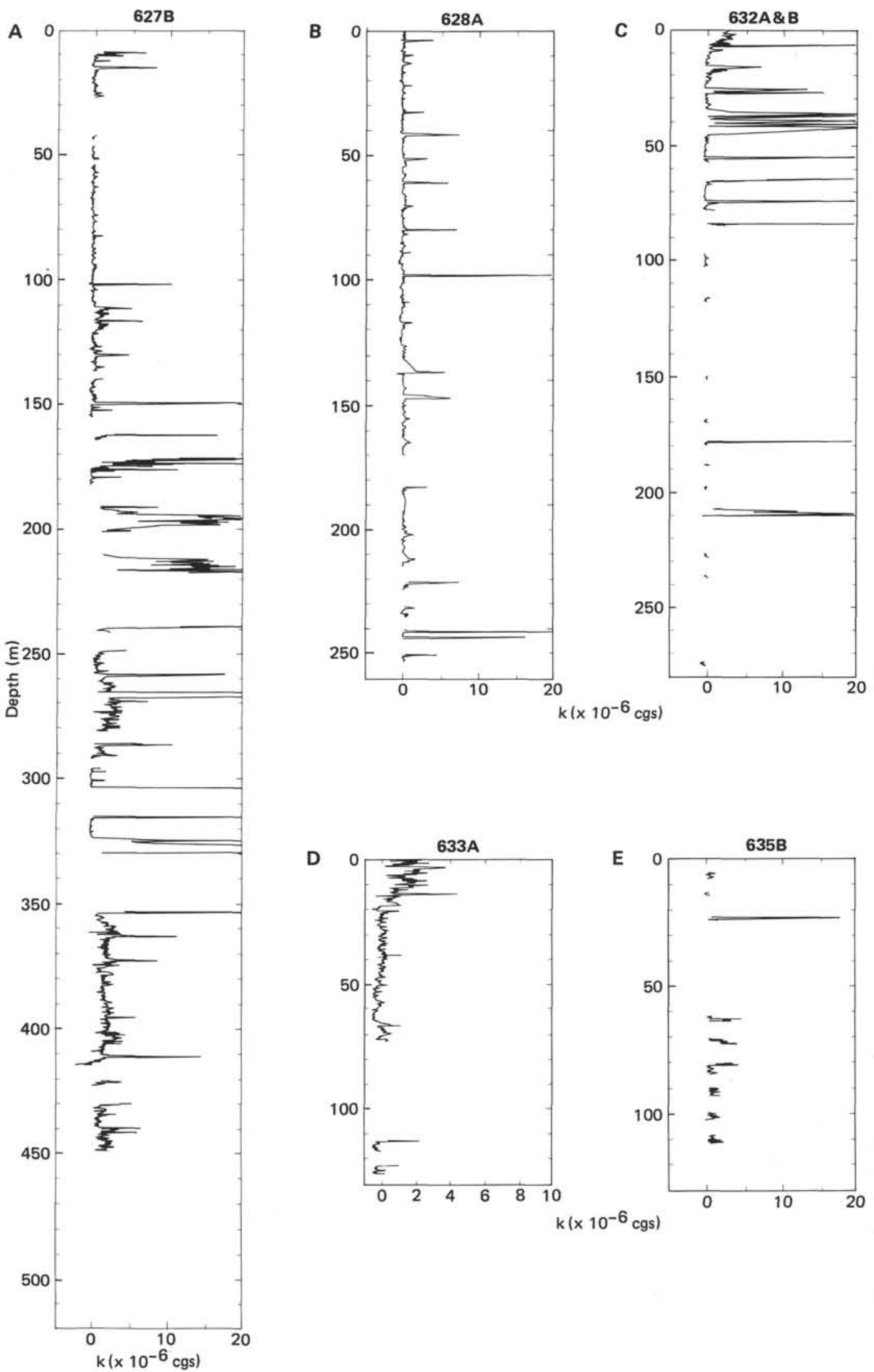

Figure 1. Plots of magnetic susceptibility vs. depth for five Leg 101 holes: (A) 627B, (B) 628A, (C) 632A and 632B, (D) 633A, and (E) 635B. Note the high-amplitude spikes caused by rust and other metal contamination of the cores. This and other figures accompanying this report are plotted as depth in meters versus susceptibility in units of $10^{-6} \mathrm{cgs}$. 


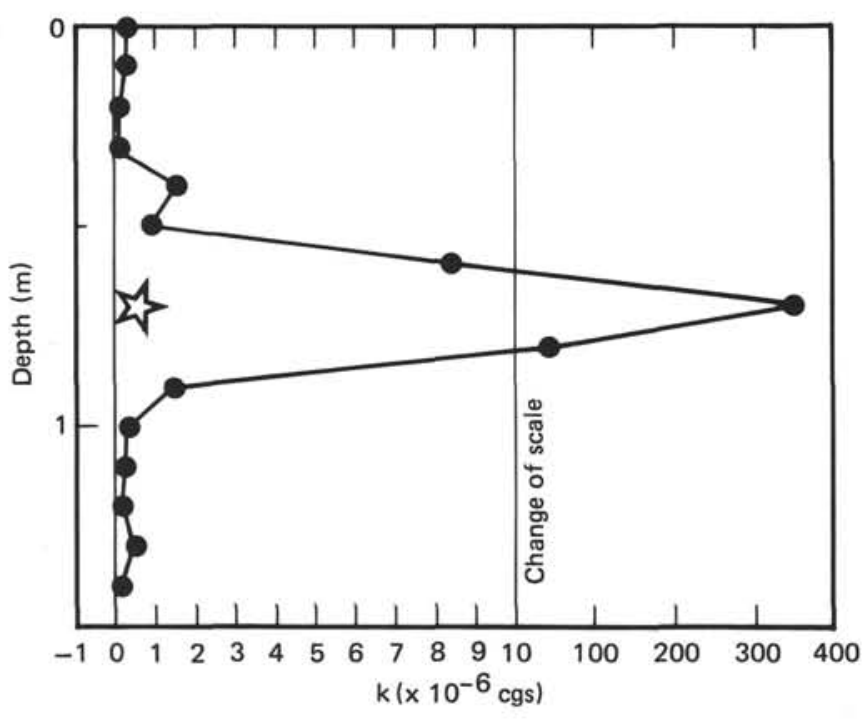

Figure 2 . Susceptibility anomaly caused by a metal fragment lodged in Core $631 \mathrm{~A}-2 \mathrm{H}$, Section 2 . The perturbation of the susceptibility readings occurs over only $70 \mathrm{~cm}$ of core. The highest value recorded was 355 $\times 10^{-6} \mathrm{cgs}$. Note the change of scale. Star shows position of the fragment.

lies, the majority show a large jump in susceptibility at the top of the core. Usually, the anomaly extends only a few tens of centimeters downcore, but as shown in Figure 3, some anomalies extend downward into the second or third core sections. Figure 4 demonstrates that most of the spurious "noise" in the susceptibility record can be eliminated simply by removing high susceptibility values that occur at the tops of cores.

Occasionally, an entire core displayed slightly higher susceptibility than the cores directly above and below it. This usually occurred when the core liner was broken. Such an anomaly was easily recognizable in the susceptibility record by an abrupt rise throughout the core to higher and more variable values. Furthermore, spikes commonly occurred near the holes formed in the core liner (Fig. 5).

Some cores contained mostly material washed down the hole from strata above the drill bit. These downhole contaminants, almost without exception, contained large amounts of disseminated rust flakes, resulting in susceptibility values one to three orders of magnitude greater than the norm. In fact, the rust contamination was so pervasive in these cores that it was possible to identify downhole contaminants with a high degree of reliability by their high, irregular susceptibilities even before the cores were split. Susceptibility records from two such cores are shown in Figure 6.

In only one case during Leg 101 was the cause of high susceptibility the sediments themselves. High and variable susceptibility values were obtained in the first $125 \mathrm{~m}$ below the ocean floor in Hole 626C. In other Leg 101 holes, this combination was usually found to be a result of downhole contamination. However, abundant glauconite and pyrite, iron-bearing minerals, were noted in the Hole $626 \mathrm{C}$ sediments. Furthermore, paleomagnetic study of several samples from these sediments indicated that they have large magnetizations with stable remanences.

\section{DISCUSSION}

Most of the metal contamination in Leg 101 cores is easily explained. Old drill pipe, unused for over a year and a half after the termination of the DSDP cruises, was pressed into service for Leg 101. This pipe was visibly rusted. In fact, the cores most consistently contaminated with rust were recovered from Hole
632A. As this hole was deeper by $915 \mathrm{~m}$ than any previously drilled on Leg 101 or on the preceding shakedown cruise, the rust probably originated in the previously unused stands of pipe added to the drill string.

The rust must originate either on the inside or the outside of the drill pipe. The large size of most of the rust flakes encountered in Leg 101 cores and the manner in which they were distributed suggest that much of the rust contamination originated on the outside of the drill string. The large rust flakes, some on the order of a centimeter in length, were often noted whenever there was significant downhole contamination. Such large flakes are unlikely to occur on the inside of the drill string, because the core traveling up and down the string would tend to keep the interior clean. On the other hand, the outside of the drill pipe is abraded by contact with the sides of the hole and the material filling in behind the drill bit. When rust is present on the outside of the drill string, it is easily dislodged and incorporated into the infill.

Figure 7 schematically explains the origins of two of the most common susceptibility anomalies. Rust is abraded from the outside of the pipe during rotary drilling and falls to the bottom of the hole when the string is raised to retrieve a core. The next core incorporates this material at its top. If there is loose material filling behind the drill bit, the rotary action of the core causes the rust flakes to be disseminated throughout this material. As the drill string is backed off during core retrieval, the downhole contaminants fall to the bottom of the hole and are subsequently cored, rust and all. The higher concentration of rust at the bottom of cores containing downhole contaminants (as seen in Fig. 6) suggests that this material forms a density-stratified slurry. The heavier fraction, including the rust flakes, sinks preferentially to the bottom of the hole. Further evidence of this process is found occasionally in other cores in which the drilling process creates spurious graded beds.

Some of the metal contaminants may also originate in the interior of the drill string. Some fragments of metal result from the abrasion and wear of the drill bit. Others may fall down the pipe. The pattern of the contamination of cores with broken liners also suggests a source of metal fragments inside the drill pipe. As seen in Figure 5, the greatest contamination of the core is often coincident with the location of a break in the liner, suggesting that the metal contaminants entered the core through the break rather than the nose of the core. On Leg 101, all of such breaks occurred on hydraulic piston cores. The sediment in the core probably became stuck causing the piston to pull a vacuum on the inside of the liner, resulting in its breakage. Water rushing into the breaks may carry with it a small amount of metal, possibly minute rust flakes from the inside of the pipe. The remarkable aspect of this phenomenon is that the whole core is usually affected, suggesting that the contaminating waters circulate throughout the entire core.

Having noted that the contamination of cores by metal fragments was a problem on Leg 101 , it is appropriate to make a few suggestions on how to minimize the problem. There is probably little that can be done to eliminate the larger metal chunks that are incorporated into cores. Abrasion of drill bits is an unavoidable part of the drilling process. Furthermore, the high stresses placed on the drilling and coring equipment make broken parts inevitable. Fortunately, these chunks occur only rarely. However, an increased awareness on the part of the drilling crew that many loose parts eventually end up in a core may help reduce this occasional nuisance.

Rust is another matter. It can be largely eliminated if the proper steps are taken. A drill string with an anti-rust coating would be an improvement. Such drill pipe is planned for use in later ODP cruises. However, it should be noted that this pipe must be coated on the outside as well as the inside. Addition- 


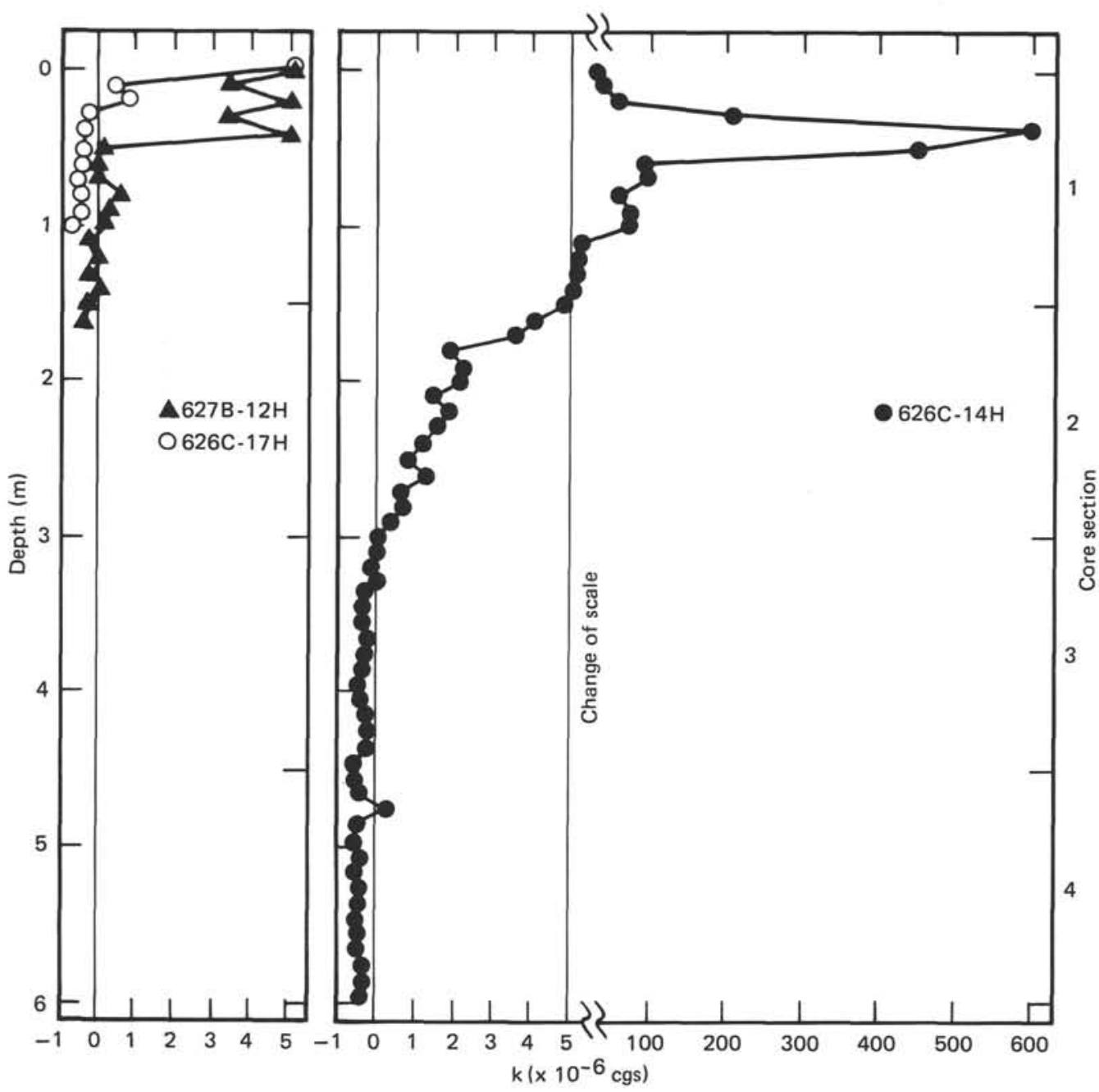

Figure 3. Three examples of the type of susceptibility anomaly that often occurred at the tops of HPC cores in Leg 101 holes. Anomalies from Cores $626 \mathrm{C}-14 \mathrm{H}, 626 \mathrm{C}-17 \mathrm{H}$, and $627 \mathrm{~B}-12 \mathrm{H}$ are shown to demonstrate the different amplitudes and depth extents observed. The susceptibility values in Core $626 \mathrm{C}-17 \mathrm{H}$ are only perturbed in the upper $20 \mathrm{~cm}$ of Section 1; however, in Core 626C-14H the anomaly extends downward through both Sections 1 and 2. Rust was visible to the naked eye only in Section 1 but not in Section 2 of this core. Note the change of scale.

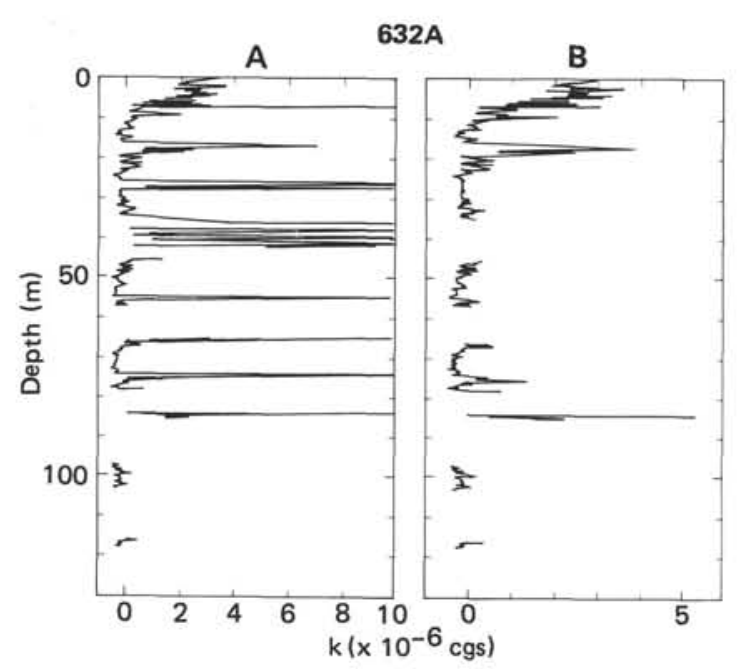

Figure 4 . Susceptibility vs. depth record from Hole $632 \mathrm{~A}$ before $(\mathrm{A})$ and after (B) susceptibility spikes occurring at the tops of cores were removed. ally, more frequent use of the drill pipe should help to keep it from building up the amount of rust encountered on Leg 101. Nevertheless, drillers of deep holes might wish to examine the extra stands of pipe retrieved from storage before they are added to the string. If rust contamination is deemed to be a problem, the pipe could be treated to remove rust before being put to use.

Lastly, the scientists on board the Resolution can minimize the impact of rust contamination simply by being aware of its existence. The susceptibility meter usually gives a reliable indication of the occurrence of metal contamination. Its use as a monitoring device can warn the scientists of cores with such problems.

\section{SUMMARY}

Magnetic-susceptibility measurements appear to be a relatively reliable method of detecting cores that have been contaminated by metal fragments. A study of susceptibility anomalies created by metal contamination on Leg 101 has found that the metal is mostly found in two forms: larger chunks, such as pins, wires, flanges, and drill-bit fragments, and rust flakes. The rust flakes are by far the most pervasive and cannot always be detect- 


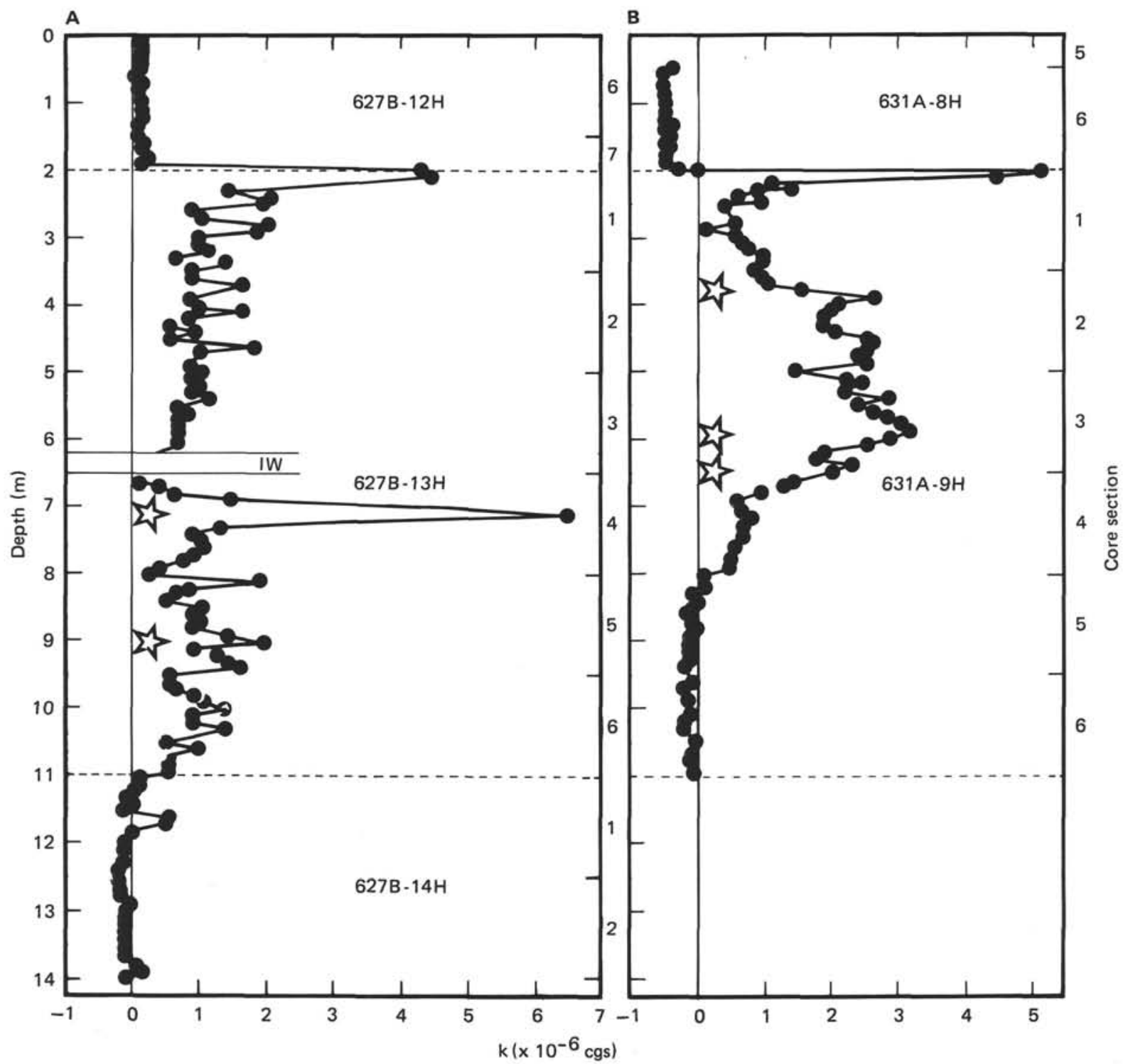

Figure 5. Susceptibility records of two cores contaminated by the breakage of the core liner: (A) $627 \mathrm{~B}-13 \mathrm{H}$ and (B) $631 \mathrm{~A}-9 \mathrm{H}$. There is an abrupt rise in susceptibility at the top of the core and higher, more varied susceptibility values are observed throughout each core. Stars indicate observed breaks in the liner. $I W$ represents core removed for interstitial-water studies.

ed with the naked eye. Although the rust can originate from both the inside and the outside of the drill string, most of the rust occurs in large flakes that appear to be abraded from the outside of the drill string from contact with the sides of the hole and the material infilling it. This rust falls to the bottom of the hole and is subsequently cored. Usually this produces a large spike in the susceptibility record at the top of a core, although large, widely scattered susceptibility values are sometimes recorded over the entirety of cores that consist primarily of material that has fallen downhole. Broken core liners usually result in the contamination of the core material with a small amount of metal. The source of these contaminants may be on the inside of the pipe. An awareness of the possibility of metallic con- tamination is needed on the part of the scientists, technicians, and crew of the JOIDES Resolution in order to minimize the damage that this problem can inflict on the scientific goals of the ODP.

\section{ACKNOWLEDGMENT}

I thank Pamela Vesterby for preparation of the illustrations accompanying this report.

\section{REFERENCE}

Collinson, D. W., 1983. Methods in Rock Magnetism and Palaeomagnetism: London (Chapman and Hall). 


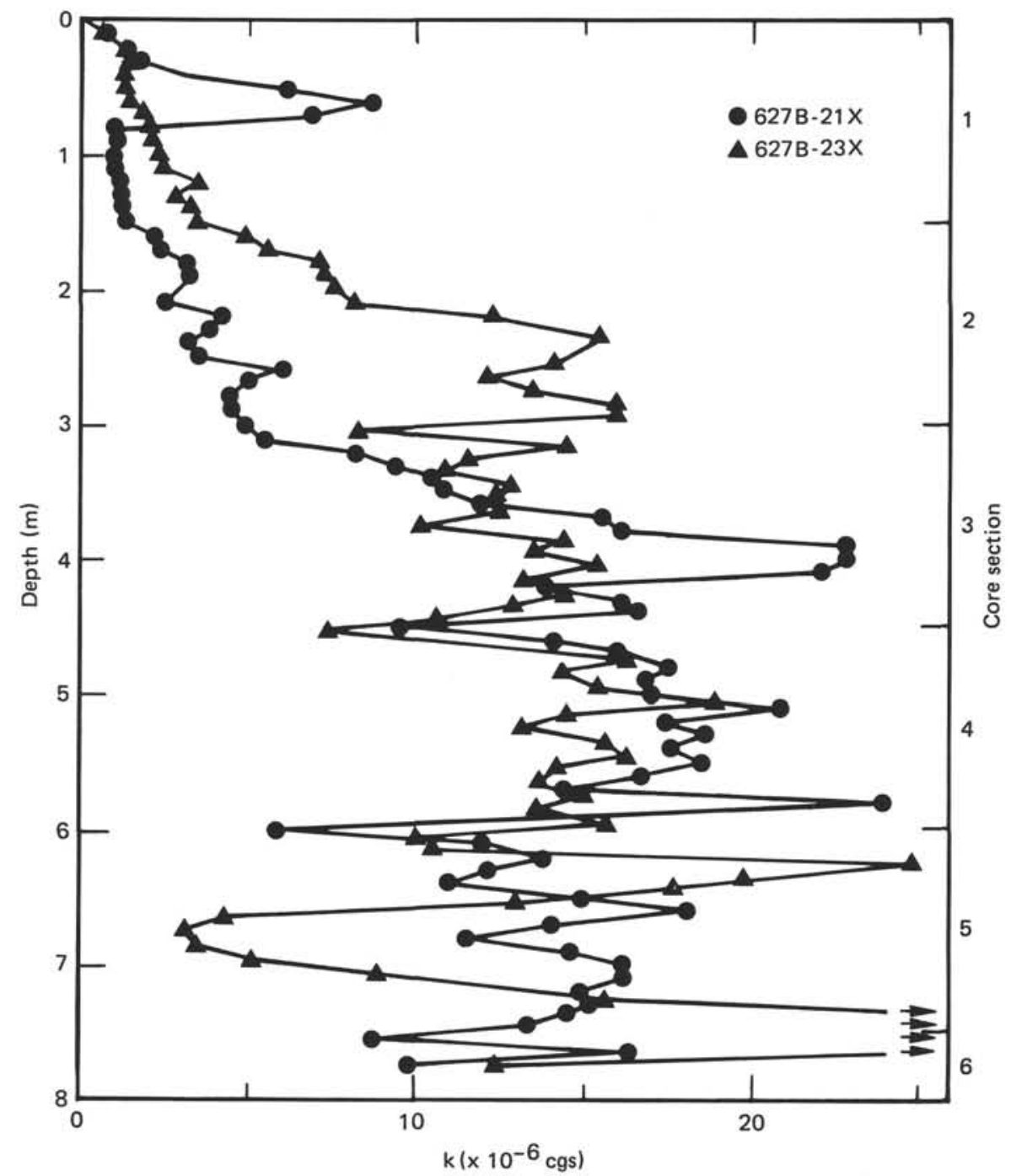

Figure 6. Susceptibility in cores consisting of downhole contamination. The susceptibility rises through the upper two sections of the core from nearly zero to high and variable readings in the bottom of each core. These records probably indicate a preferential settling of rust flakes to the bottom of a slurry of water and downhole contaminants. 

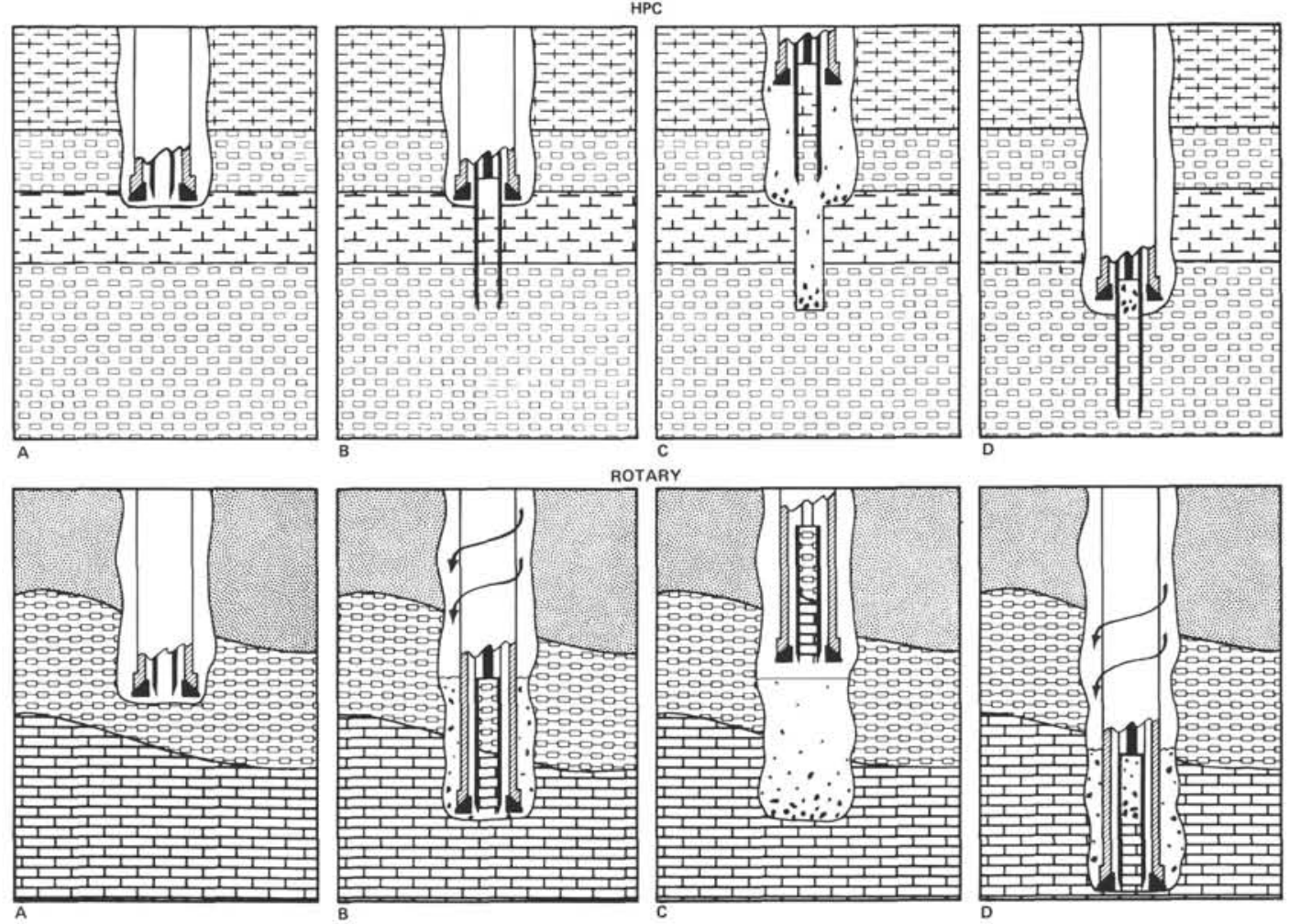

Figure 7. Schematic cross sections illustrating the manner in which most rust contamination occurs. Top: The HPC is shot ahead of the drill bit to obtain a core (A, B); as the core is retrieved, the drill bit is raised off the bottom of the hole $(C)$; rust abraded from the outside of the drill pipe falls to the bottom of the hole at this point or as the drill advances by rotary motion to the bottom of the hole; in (D) the rust that settled to the bottom of the hole is sampled at the top of the core in the next HPC shot. Bottom: The turning action of the rotary core bit stirs a slurry of water and downhole contaminants, disseminating abraded rust flakes throughout the slurry (A, B); as the bit is raised for core retrieval, the slurry falls to the bottom of the hole and stratifies, the larger and heavier fragments (including rust) sinking to the bottom (C); downhole contaminants and rust are cored as the drill advances (D). 